between this polymer and silanol groups may be of interest in explaining its chemotherapeutic action. In a preliminary communication ${ }^{2}$, it has been shown that monosilicic acid in concentrations below 0.01 molar produces a bathochromic shift in the ultraviolet absorption spectrum of poly-2-vinylpyridine 1-oxide. A similar shift is not observed when monosilicic acid is added to 2-ethylpyridine 1-oxide. A slight shift in the spectrum of poly-4-vinylpyridine-1-oxide in the presence of monosilicic acid indicates that there is also some interaction between the 4-isomer and monosilicic acid. These deductions have been confirmed by viscosity measurements. The interaction presumably involves hydrogen-bond formation between the $\mathrm{N}$-oxide group and the silanol group.

Nash, Allison and Harington ${ }^{3}$ have shown that there is also interaction between poly-2-vinylpyridine 1-oxide and polysilicic acid because a precipitate is formed whon solutions of the two are mixed, and this again indicates hydrogen bonding. The implied correlation between hydrogen bonding and chemotherapeutic activity has been examined by synthesizing a number of other pyridine oxide polymers, and the ability of these and of poly- $N$ vinylpyrrolidone to precipitate polysilicic acid has been observed. The ability of each to counteract the cytotoxic effects of silica was measured by adding each polymer to a culture of peritoneal macrophages to which silica powder had been added and comparing the survival times of the cells. (These tests were carried out by Dr Beck and Miss Sack in the Institut für Lufthygiene, Düsseldorf.) The results are summarized in Table 1 . There is apparently no correlation between the ability of a polymer to inhibit the cytotoxic effect of quartz and its ability to precipitate polysilicic acid.

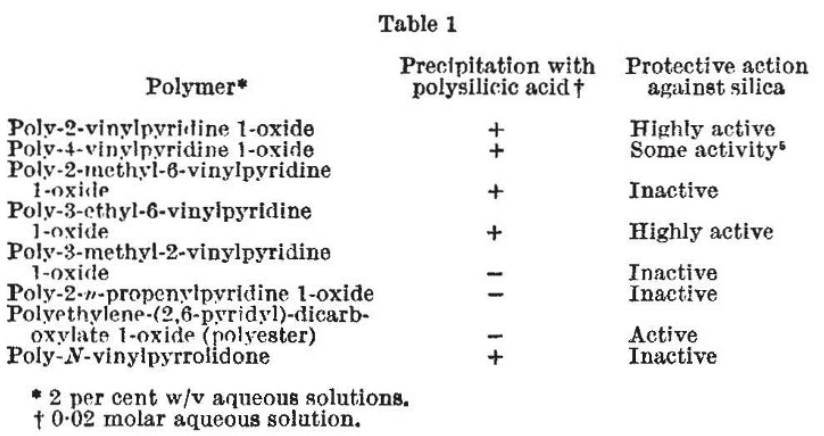

Further studies (unpublished) on the effect of monosilicic acid on the viscosity of solutions of poly-2-vinylpyridine 1-oxide and poly-4-vinylpyridine 1-oxide indicate that, while the complex formed by the first polymer is stable up to $60^{\circ} \mathrm{C}$, that formed by the second is much less stable above $20^{\circ} \mathrm{C}$. It seems that loose interchain crosslinks and links between proximate parts of a randomly coiled polymer chain are formed by monosilicic acid with poly-4-vinylpyridine oxide but that monosilicic acid is more intimately bound to poly-2-vinylpyridine oxide. Interaction between oxygen and alkyl group in 2 -methyl pyridine oxide has been demonstrated ${ }^{4}$. The type of bonding is probably present in poly-2-vinylpyridine 1-oxide because this polymer has a lower $p K_{a}$ value than the 4-isomer. A model shows that the polymer structure would then be very compact with the oxygen atoms aligned so that monosilicic acid could become attached to the polymer by two or possibly three hydroxyl groups. Cross-linking would be less likely with poly-2-vinylpyridine oxide than with poly-4-vinylpyridine oxide.

It seems probable that the ability of poly-2-vinylpyridine oxide to exert a protective action against silica depends not merely on its ability to form a hydrogen bonded complex, for most $\mathrm{N}$-oxides will form such com- plexes, but on the stability of the complex which is formed.

This work was supported by the Asbestosis Research Council and the Science Research Council.
P. F. HoLT
H. LINDSAY
E. T. Nasrallah

Department of Chemistry, University of Reading.

Received September 13, 1967.

${ }^{1}$ Schlipköter, H. W., Mrinisterprasident des Landes Nordrhein-WestfalenLundesame fü̈r Forschwng. Jahrbuch 1964, 451.

"Holt, P. F., and Nasrallah. F. T., Nature.211. s78 (1966).

Sash, J., Altison, A. C., and Harington. J. S., N'ature, 210, 259 (1966).

- Ikekawa, N., and Yoshiro, S., Pharmacol. Bull. Janan. 2, $4(10$ (1954).

${ }^{5}$ Schlipköter, H. W.. and Brockhaus, A., Fortschritte der Staublungenforschungen, 377 (1963).

\section{Carcinogens in Chinese Incense Smoke}

CONSIDERATION of the high incidence of naso-pharyngeal cancer among the Chinese ${ }^{1}$ led us to search for carcinogenic constituents in condensates from burning Chinese incense. Using thin-layer and column chromatography, several polycyclic aromatic hydrocarbons, including 3,4-benzopyrene, have been detected by ultraviolet absorption spectra. The 3,4-benzopyrene content was estimated fluorimetrically ${ }^{2}$ to be of the order $0.4 \mu \mathrm{g} / \mathrm{stick}$ of incense. The free radical content of the tar condensates was estimated by Dr A. Horsfield of Varian Associates Lt.d. to be approximately $1.3 \times 10^{15}$ stable electrons/g (comparable with the figure $1 \times 10^{15} / \mathrm{g}$ obtained for cigarette $\operatorname{tar}^{3}$ ).

A search for nitrosamines in the condensate by the polarngraphic method ${ }^{4}$ gave negative results, but the method of Preussmann et al..$^{5}$, and the Griess reagent, gave a salmon pink spot, $R_{F} 0 \cdot 35$, on thin-layer chromatography (hexane: ether : dichloromethane, $4: 3: 2$ ).

The same colour was, however, obtained by spraying the plate with sulphanilic acid ( 1 per cent in 30 per cent acetic acid) without the need of previous irradiation and of the second component of the Gricss reagent, 1-naphthylamine.

Nitrosamines do not give a colour with the sulphanilic acid reagent, but aromatic aldehydes give chiefly yellow colours. Furfuraldehyde which gives a slowly developing red colour similar to that of the unknown constituent of incense condensate has, however, a different $R_{F}$ on thinlayer chromatography.

The colours given by aromatic aldehydes with sulphanilic acid should be borne in mind when applying the Griess reagent for the detection of nitrosamines according to the procedure of Preussmann et al. ${ }^{5}$.

We thank Professor K. Shanmugaratnam for the Chinese incense.

R. SChOFNTAL

S. Grbbard

MRC Toxicology Research Unit,

Woodmansterne Road,

Carshalton, Surrey.

${ }^{1}$ Cancer of the Nasopharynx, YTCC Monomraph Series, 1 (edit. hy Mnir, C. S., and Shanmugaratnam. K.) (Munksgaard, Copenhagen. 196i).

"Duhoir, L., and Monkman, J. L., Intern. J. Air IVater Pollution, 9. 131 (1965).

${ }^{3}$ Lvons, M. J., Gibson. J. F.. and Ingram. D. .J. F.. Nature. 181, 1003 (1958).

- Heath, D. F., and Jarvis, J. A. E., A nalyst, 80, 613 (1955).

- Preussmann, R., Neurath, G., Wulf-Torentzen, G., Daiber, D., and Hengy, H., Z. Anal. Chem., 202, 187 (1964). 